\title{
Enhancement of Island Microgrid Operation by Frequency-sensor-based Controller of Battery Storage System
}

\author{
Cheng-Ting Hsu, ${ }^{*}$ Tsun-Jen Cheng, and Hung-Ming Huang \\ Department of Electrical Engineering, Southern Taiwan University of Science and Technology, \\ Yung-Kang, Tainan 71005, Taiwan
}

(Received October 15, 2019; accepted February 10, 2020)

Keywords: frequency-sensor-based controller, battery storage system, microgrid, load shedding

In this paper, we proposed a frequency-sensor-based controller (FSBC) of the battery storage system (BSS) to regulate the frequency variation of an island microgrid with a very high penetration level of renewable energy sources. We selected the Kinmen Island microgrid for our study. Grid data including the network topology, system load profile, photovoltaic power generation (PVPG), wind power generation (WPG), and load shedding strategy are collected and analyzed. Then, the mathematical models of the governor and exciter of diesel generators are confirmed and derived. The BSS with an FSBC is designed and applied to enhance the operation of the microgrid. After that, the transient stability analysis is carried out by considering various operation scenarios and contingency events, such as the tripping of diesel and wind generators or the ramping change in PVPG power output. Moreover, the FSBC of the BSS with different rating capacities is included in the simulation process to improve the frequency variation of the microgrid by regulating its active power output rapidly. It is found that the proposed FSBC of the BSS is very effective in enhancing the operation of the grid and preventing load shedding.

\section{Introduction}

The development of renewable energy is considered the most important issue for a sustainable environment. It helps reduce greenhouse gas emissions effectively. Among various renewable energy resources, wind power and solar energy have been identified as having the most development potential. However, both wind power generation (WPG) and photovoltaic power generation (PVPG) are intermittent and nondispatchable power sources. ${ }^{(1,2)}$ The power output can vary markedly owing to the wind and solar irradiance fluctuations. It can have a considerable impact on low-power or small-island-power systems as the WPG and PVPG have a higher penetration level of power output. In particular, the frequency of the small islands may be affected severly owing to the power variation of the WPG and PVPG and may result in the tripping of the load and generators.

A load frequency control method ${ }^{(3,4)}$ can be applied to support the operation of a microgrid. However, more and more battery storage systems (BSSs) are currently working on the power

*Corresponding author: e-mail: cthsu@stust.edu.tw

https://doi.org/10.18494/SAM.2020.2693 
grid. Typically, a BSS includes a battery storage unit (BSU) and a power conversion system (PCS). By appropriately controlling the PCS, the BSS can adjust its active and reactive powers continuously and rapidly. Generally, the BSS can execute ancillary services to support power grid operation. ${ }^{(5,6)}$ It has many functions, ${ }^{(7-9)}$ such as frequency regulation, voltage support, spin/nonspin reserve, energy arbitrage, and backup power. In this study, we installed the BSS to improve frequency variation to prevent the unnecessary load shedding due to the power variation of the WPG and PVPG.

There are many small offshore islands in Taiwan. Diesel engine generator units currently dominate the power system of these islands. ${ }^{(10,11)}$ They may increase greenhouse gas emissions and have a higher fuel cost. Therefore, it is very helpful to reduce the system fuel cost by installing renewable energy generators. However, it is very important to know the impact of renewable energy power generation on isolated small-scale power systems for safety operation consideration. In this work, we selected the Kinmen Island microgrid for our study. The disturbance events of WPG tripping, all PVPG power output variations with a ramp rate $(\mathrm{RR})^{(12,13)}$ of $100 \% / \mathrm{s}$, and the diesel generator tripping are evaluated by transient stability analysis. To enhance system reliability, a frequency-sensor-based controller (FSBC) of a BSS with different capacities is applied to improve the system frequency response to prevent load shedding.

\section{Study Island Power System}

\subsection{System configuration}

Figure 1 shows the one-line diagram of the study power system. There are two diesel power plants (DPPs) in the system. DPP\#1 has eight diesel generators. The rating capacities are 7.91 MW for the G1-G4 units and 8.25 MW for the G5-G8 units. DPP\#2 has six diesel generators. The rating capacity is $3.168 \mathrm{MW}$ for the G1-G2 units. In addition, 3.512 and $3.488 \mathrm{MW}$ are those for the G3 and G4-G6 units, respectively. Electric power supply from DPP\#1 is transformed to the $22.8 \mathrm{kV}$ voltage level through step-up transformers, whereas that from DPP\#2 is transformed to $11.4 \mathrm{kV}$. Furthermore, the loading is represented as L1-L6. It is about 19.48 MW in the winter night (WN), which is the lightest loading of the island. Also, 30.46 and 57.24 MW are observed during daytimes in winter and summer, respectively.

\subsection{Renewable energy on island}

The amount of renewable energy on the island is increasing rapidly. Now, two wind generators are installed at bus 1106 with a rating capacity of $2 \mathrm{MW}$ each. Also, a new WPG plant with a total capacity of $2.6 \mathrm{MW}$ is currently being considered. Figure 2 shows the average hourly energy generation of a wind turbine at the WPG1 plant. Statistical data are collected every three years. From these data, the largest average hourly energy generation of about $800 \mathrm{kWh}$ for a $2 \mathrm{MW}$ wind turbine was observed in winter. Furthermore, the PVPG installation capacity was about $5 \mathrm{MWp}$ in 2017. Moreover, the value increased to 8.2 MWp in 2019. Figure 3 shows the average hourly energy generation of a $528 \mathrm{kWp}$ PVPG plant from June to August. The largest average energy generation of about $280 \mathrm{kWh}$ was observed at 13:00 in July. 


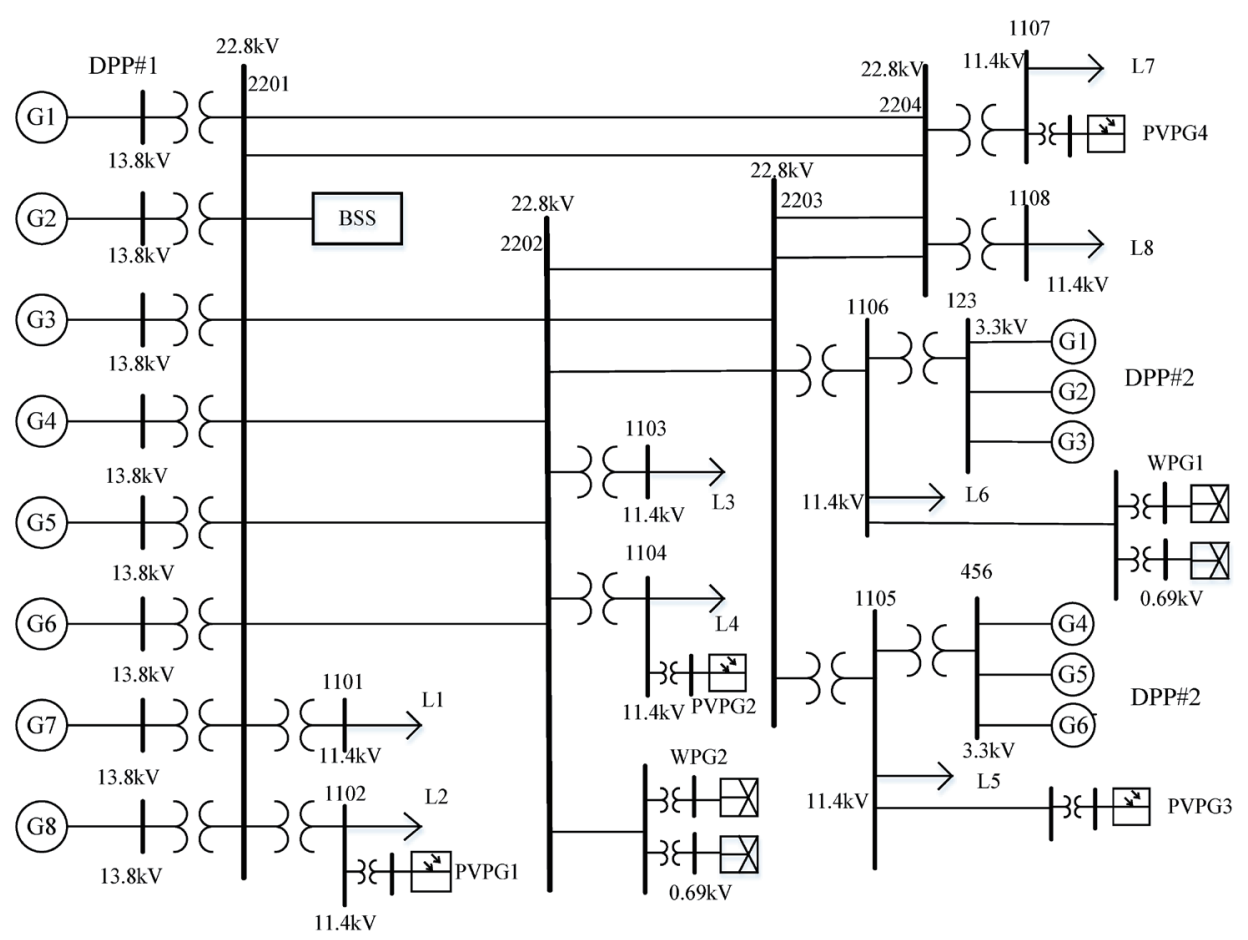

Fig. 1. One-line diagram of study power system.

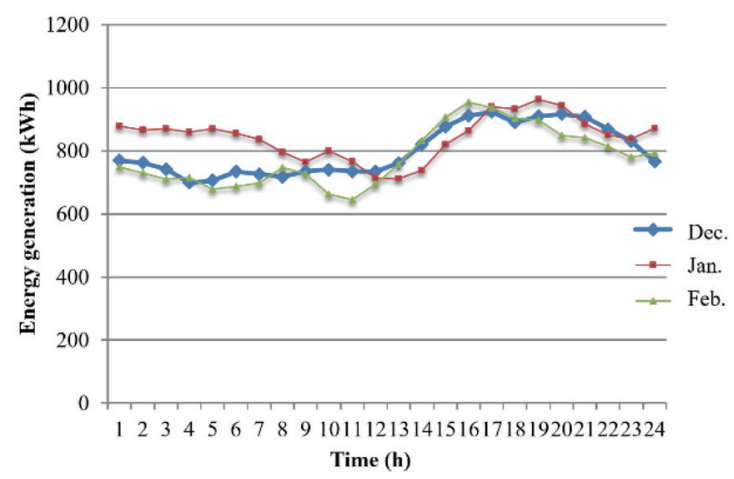

Fig. 2. (Color online) Average hourly energy generation of WPG plant.

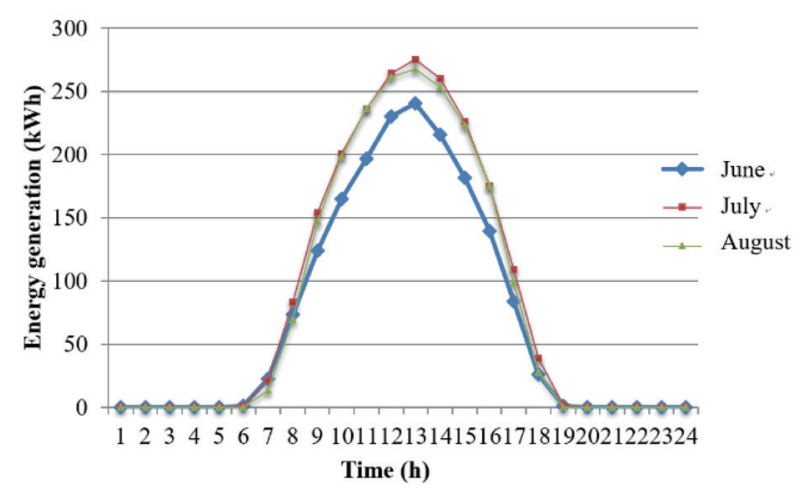

Fig. 3. (Color online) Average hourly energy generation of PVPG plant.

\subsection{Modelling of diesel generators}

To know the dynamic response of the power system after the occurrence of a disturbance event, the control models of diesel generators should be collected and verified well. In this study, all the diesel generator units have the same governor control model, as shown in Fig. 4. ${ }^{(14)}$ All the units are operated as droop models except for the G5-G8 units in the isochronous mode. Table 1 gives the parameters of the governor control model for all units. 


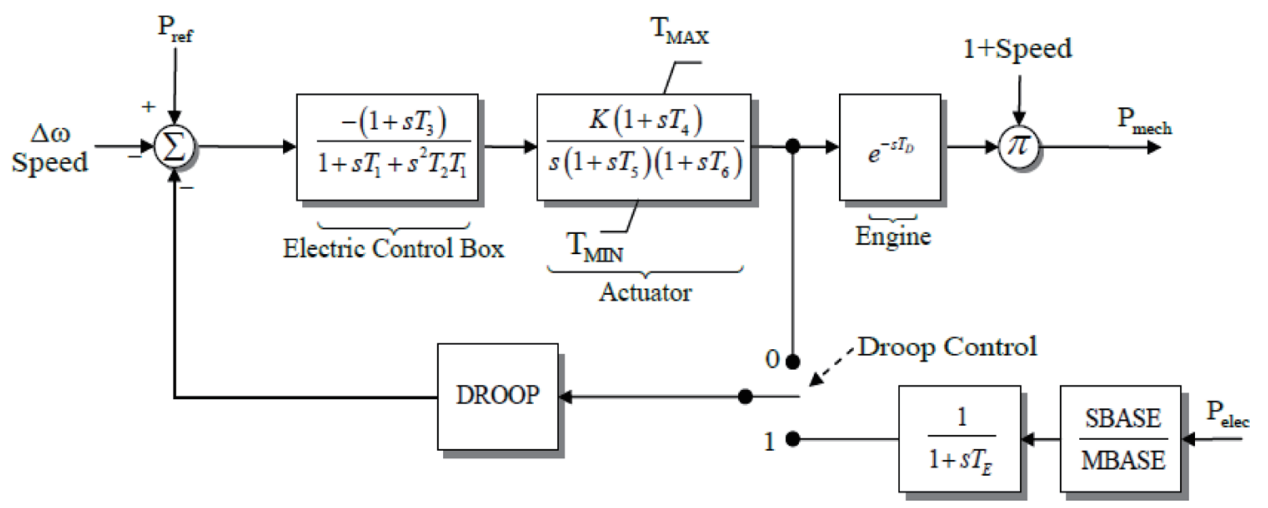

Fig. 4. Governor control block diagram of diesel generators.

Table 1

Parameters of governor control model.

\begin{tabular}{lcccccccccc}
\hline Gen No. & $\begin{array}{c}T_{1}-T_{3} \\
(\mathrm{~s})\end{array}$ & $\begin{array}{c}K \\
(\mathrm{p} . \mathrm{u} .)\end{array}$ & $\begin{array}{c}T_{4} \\
(\mathrm{~s})\end{array}$ & $\begin{array}{c}T_{5} \\
(\mathrm{~s})\end{array}$ & $\begin{array}{c}T_{6} \\
(\mathrm{~s})\end{array}$ & $\begin{array}{c}T_{D} \\
(\mathrm{~s})\end{array}$ & $\begin{array}{c}T_{\max } \\
(\mathrm{p} . \mathrm{u} .)\end{array}$ & $\begin{array}{c}T_{\min } \\
\text { (p.u.) }\end{array}$ & $\begin{array}{c}T_{E} \\
(\mathrm{~s})\end{array}$ & $\begin{array}{c}\text { DROOP } \\
\text { (p.u.) }\end{array}$ \\
\hline $\begin{array}{l}\text { G1-G4 } \\
\text { in DPP\#1 }\end{array}$ & 0 & 1.2 & 0.20 & 0.17 & 0 & 0.055 & 1 & 0.06 & 0.15 & 0.05 \\
$\begin{array}{l}\text { G5-G8 } \\
\text { in DPP\#1 }\end{array}$ & 0 & 1.5 & 0.8 & 0.17 & 0 & 0.045 & 1 & 0 & N/A & N/A \\
$\begin{array}{l}\text { G1-G6 } \\
\text { in DPP\#2 }\end{array}$ & 0 & 0.1 & 0 & 1 & 0 & 0.055 & 1 & 0.06 & 0.15 & 0.05 \\
\hline
\end{tabular}

\subsection{Load shedding setting}

To prevent the blackout of the power system due to insufficient power supply, a welldesigned load shedding scheme is necessary. A traditional low-frequency load shedding scheme with four shedding steps is currently applied to the island microgrid. The frequencies for steps $1-4$ are set to $57.3,57,56.5$, and $56 \mathrm{~Hz}$, respectively.

\subsection{FSBC of BSS}

A BSS can be used to support the operation of the diesel generators by regulating their active and reactive power outputs rapidly. However, only active power compensation is discussed in this paper. A high-resolution frequency sensor is installed near the BSS site to detect system frequency in real time. Figure 5 gives the control block diagram of the BSS. The BSS will regulate its final power output $\left(P_{\text {out }}\right)$ by taking the frequency as a feedback signal. A dead-band (DB) function is designed to allow the insensitivity reaction and prolong the battery life. In the figure, $K$ is the gain and $T_{1}$ is the time delay. Also, the initial power output of the PCS is represented as $P_{0} . P_{\min }$ and $P_{\max }$ are the minimum and maximum power output capabilities of the PCS, respectively. Table 2 gives the parameters of the proposed BSS control model for a $1 \mathrm{MW}$ PCS. The low and high frequencies of DB are set at 59.5 and $60.2 \mathrm{~Hz}$, respectively. 


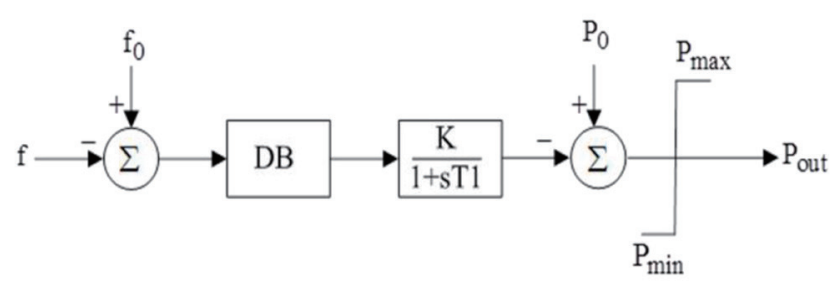

Fig. 5. Control model of BSS.

Table 2

BSS control model parameters.

\begin{tabular}{cccccc}
\hline$T_{1}(\mathrm{~s})$ & $K(\mathrm{pu})$ & $P_{\min }(\mathrm{MW})$ & $P_{\max }(\mathrm{MW})$ & $f_{\min }(\mathrm{Hz})$ & $f_{\max }(\mathrm{Hz})$ \\
\hline 0.065 & 200 & -1 & 1 & 59.5 & 60.2 \\
\hline
\end{tabular}

It is important to ensure the accuracy of the data above. In this paper, all the system data, such as loading, parameters of the governors, frequencies set, and parameters of the BSS, are provided and verified by the power company.

\section{Steady-state Operation Scenarios and Transient Stability Analysis Events}

In this section, Cyme Psaf software ${ }^{(15)}$ is used for the steady-state and transient analyses. We selected three loading conditions in WN, winter day (WD), and summer day (SD) for this study. Different combinations of the diesel generators are used to meet the loading for each condition in the steady-state analysis. After that, three different disturbance events are used to execute the transient stability analysis. Furthermore, the BSS with different PCS capacities is also considered in the computer simulation to know its effect on the frequency support with the proposed control model.

\subsection{Case WN}

The study case WN condition has the lightest loading of $19.48 \mathrm{MW}$. Also, the power outputs of WPGs and PVPGs are assumed as 6.6 and $0 \mathrm{MW}$, respectively. There are two operating dispatches for diesel power plants. One should have three generators in service, while the other should have four generators in DPP\#1.

Two disturbance events are selected for transient analysis. The first one is the tripping of one generator in DPP\#1. After that, the tripping of all the 6.6 MW WPG systems is also considered. Table 3 gives the operating scenarios and disturbance events of the study case WN.

The BSS with various PCS capacities is used to support the operation of the island microgrid as the system frequency dropped below the set DB frequency of $59.5 \mathrm{~Hz}$. Table 4 gives the simulation results of the lowest and highest frequencies for each case. From these results, the lowest frequency below $57.3 \mathrm{~Hz}$ was found to appear in many simulation cases when the PCS capacity of the BSS was not sufficiently large. Therefore, a PCS capacity of $3 \mathrm{MW}$ is necessary to prevent load shedding. 
Table 3

Operating scenarios and events for study case WN.

\begin{tabular}{lccc}
\hline Case & Generators in service & Power output of REs (MW) & Disturbance event \\
\hline WN1A & 3 in DPP\#1 & $\begin{array}{l}\text { WPG:6.6 } \\
\text { PVPG:0 }\end{array}$ & Tripping of all WPG systems \\
\hline WN1B & 3 in DPP\#1 & $\begin{array}{l}\text { WPG:6.6 } \\
\text { PVPG:0 }\end{array}$ & Tripping of one generator \\
\hline WN2A & 4 in DPP\#1 & $\begin{array}{l}\text { WPG:6.6 } \\
\text { PVPG:0 }\end{array}$ & Tripping of all WPG systems \\
\hline WN2B & 4 in DPP\#1 & $\begin{array}{l}\text { WPG:6.6 } \\
\text { PVPG:0 }\end{array}$ & Tripping of one generator \\
\hline
\end{tabular}

Table 4

Highest and lowest frequencies for study case WN.

\begin{tabular}{lccc}
\hline Case & Lowest frequency $(\mathrm{Hz})$ & Highest frequency $(\mathrm{Hz})$ & PCS capacity of BSS (MW) \\
\hline \multirow{4}{*}{ WN1A } & 55.76 & 61.42 & 0 \\
& 56.44 & 60.33 & 1 \\
& 57.09 & 60.00 & 2 \\
& 57.71 & 60.01 & 3 \\
\hline \multirow{2}{*}{ WN1B } & 56.24 & 61.18 & 0 \\
& 57.14 & 60.16 & 1 \\
& 58.00 & 60.14 & 2 \\
\hline & 58.77 & 60.14 & 3 \\
WN2A & 56.79 & 60.90 & 0 \\
& 57.29 & 60.24 & 2 \\
& 57.77 & 60.00 & 3 \\
\hline \multirow{2}{*}{ WN2B } & 58.23 & 60.00 & 0 \\
& 58.05 & 60.51 & 2 \\
& 58.63 & 60.06 & 3
\end{tabular}

\subsection{Case WD}

The study case WD condition has a loading of $30.46 \mathrm{MW}$. The power output of WPGs is assumed as $6.6 \mathrm{MW}$. Moreover, the power output of PVPGs is assumed as $6.56 \mathrm{MW}$, which is about $80 \%$ of the installed capacity. There are two operating dispatches for diesel power plants. One should have three generators in service, while the other should have four generators in DPP\#1.

Three disturbance events are selected for transient analysis. The tripping events of one generator in DPP\#1 and all WPG systems are the same as those in case WN. Also, one new disturbance event of all the power outputs of PVPGs with an RR of $100 \% / \mathrm{s}$ is added. Table 5 gives the operating scenarios and disturbance events of the study case WD.

Table 6 gives the lowest and highest frequencies for each simulation case. Similar simulation results are observed, that is, the lowest frequency below $57.3 \mathrm{~Hz}$ appeared in many simulation cases when the PCS capacity of the BSS was not sufficiently large. Therefore, a PCS capacity of $3 \mathrm{MW}$ is necessary to prevent load shedding. A more detailed description of each simulation case is given below. 
Table 5

Operating scenarios and events for study case WD.

\begin{tabular}{lccc}
\hline Case & Number of generators in service & Power output of REs (MW) & Disturbance event \\
\hline WD1A & 3 in DPP\#1 & $\begin{array}{c}\text { WPG:6.6 } \\
\text { PVPG:6.56 }\end{array}$ & Tripping of all WPG systems \\
\hline WD1B & 3 in DPP\#1 & $\begin{array}{c}\text { WPG:6.6 } \\
\text { PVPG:6.56 }\end{array}$ & Tripping of one generator \\
\hline WD1C & 3 in DPP\#1 & $\begin{array}{c}\text { WPG:6.6 } \\
\text { PVPG:6.56 }\end{array}$ & $\begin{array}{c}\text { All PVPGs occur } \\
\text { with an RR of } 100 \% / \mathrm{s}\end{array}$ \\
\hline WD2A & 4 in DPP\#1 & $\begin{array}{c}\text { WPG:6.6 } \\
\text { PVPG:6.56 }\end{array}$ & Tripping of all WPG systems \\
\hline WD2B & 4 in DPP\#1 & $\begin{array}{c}\text { WPG:6.6 } \\
\text { PVPG:6.56 }\end{array}$ & Tripping of one generator \\
\hline WD2C & 4 in DPP\#1 & $\begin{array}{l}\text { WPG:6.6 } \\
\text { PVPG:6.56 }\end{array}$ & $\begin{array}{c}\text { All PVPGs occur } \\
\text { with an RR of } 100 \% / \mathrm{s}\end{array}$ \\
\hline
\end{tabular}

Table 6

Highest and lowest frequencies for study case WD.

\begin{tabular}{lccc}
\hline Case & Lowest frequency $(\mathrm{Hz})$ & Highest frequency $(\mathrm{Hz})$ & PCS capacity of BSS (MW) \\
\hline \multirow{3}{*}{ WD1A } & 55.67 & 60.77 & 0 \\
& 56.37 & 60.06 & 1 \\
& 57.05 & 59.50 & 2 \\
& 57.70 & 59.50 & 3 \\
WD1B & 54.72 & 55.59 & 0 \\
& 55.65 & 59.32 & 1 \\
& 56.60 & 59.42 & 2 \\
& 57.52 & 59.45 & 3 \\
WD1C & 56.24 & 62.74 & 0 \\
& 56.83 & 60.52 & 2 \\
& 57.41 & 60.33 & 3 \\
\hline \multirow{2}{*}{ WD2A } & 57.98 & 60.27 & 0 \\
& 56.75 & 61.03 & 1 \\
& 57.26 & 60.28 & 2 \\
\hline & 57.76 & 60.00 & 3 \\
WD2B & 58.24 & 60.00 & 0 \\
& 57.29 & 60.84 & 2 \\
& 57.92 & 60.11 & 3 \\
\hline WD2C & 58.51 & 60.05 & 0 \\
& 59.02 & 60.05 & 1 \\
& 57.22 & 61.93 & 3 \\
\hline
\end{tabular}

\subsubsection{Case WD2A}

This case assumes the tripping of all the WPG systems at $1 \mathrm{~s}$ with a total capacity of 6.6 MW. Then, the transient stability is analyzed while considering the compensation effectiveness of the BSS. After the tripping of all the WPG systems, the frequency declined rapidly as shown in Fig. 6. It is observed that the system frequency dropped to the lowest value of $56.75 \mathrm{~Hz}$ and reached the highest value of $61.03 \mathrm{~Hz}$ for the system without the compensation by the BSS. The 


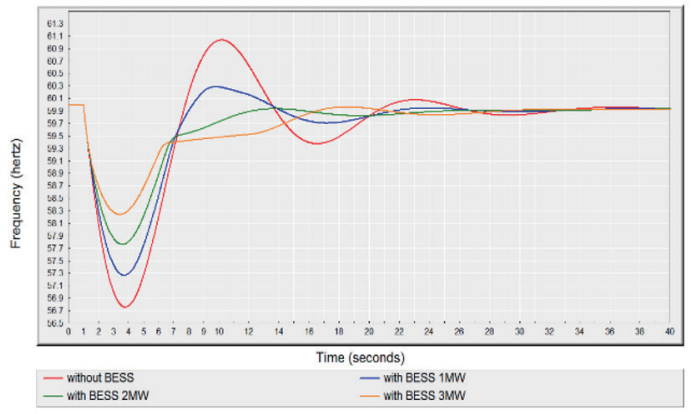

Fig. 6. (Color online) Frequency response curves of case WD2A.

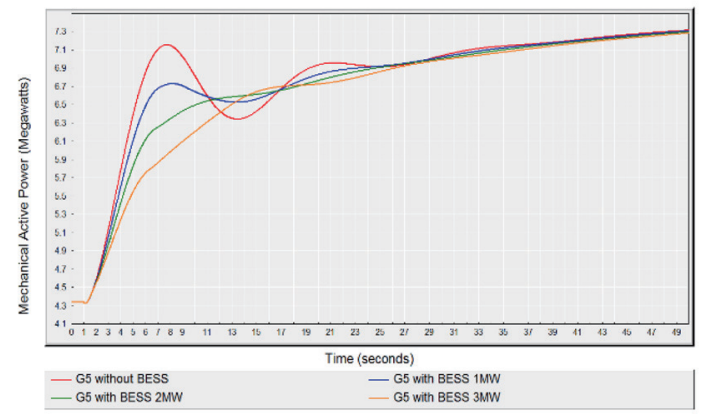

Fig. 7. (Color online) G5 mechanical power response curves of case WD2A.

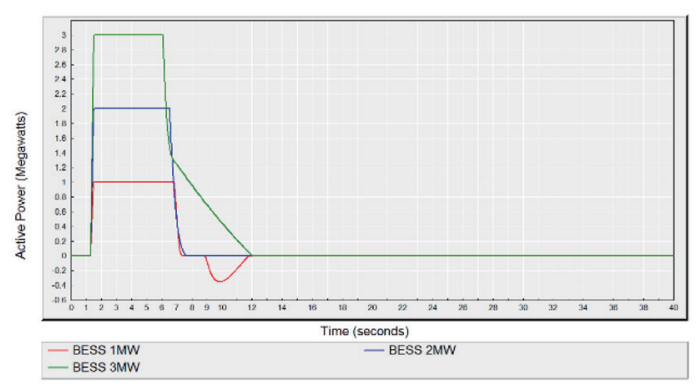

Fig. 8. (Color online) BSS power response curves of case WD2A.

frequencies dropped to the lowest values of $57.26,57.76$, and $58.24 \mathrm{~Hz}$ for the BSS with 1,2 , and 3MW PCS capacities, respectively. It is also found that the over-frequency phenomena can be damped well by the regulation of the BSS. Figure 7 shows the mechanical power responses of G5 at DPP1. The rising ramping rate is smaller for the BSS with a larger PCS capacity. Moreover, the BSS discharged rapidly to its maximum power output of the PCS as shown in Fig. 8, then returned to its initial value after the frequency recovered to the DB of 59.5-60.2 Hz.

\subsubsection{Case WD2C}

This disturbance event assumed that all the power outputs of PVPGs occurred with an RR of $100 \% / \mathrm{s}$ as shown in Fig. 9. After the output power disturbance of PVPG plants, the frequency declined rapidly as shown in Fig. 10. It is observed that the system frequency dropped to the lowest value of $57.22 \mathrm{~Hz}$ and reached the highest value of $61.93 \mathrm{~Hz}$ for the system without the compensation by the BSS. The frequencies dropped to the lowest values of 57.63, 58.02, and $58.39 \mathrm{~Hz}$, and increased to the highest values of $61.12,60.48$, and $60.35 \mathrm{~Hz}$ for the BSS with 1,2, and 3 MW PCS capacities, respectively. Also, the mechanical power variation of G5 is smaller for the BSS with a larger PCS capacity, as shown in Fig. 11. Figure 12 gives the responses of BSS power output. The BSS discharged rapidly to its maximum power output of the PCS as the frequency decreased to $59.5 \mathrm{~Hz}$, and then started to charge as the frequency increased to 60.2 Hz. The power output finally returns to its initial value. 


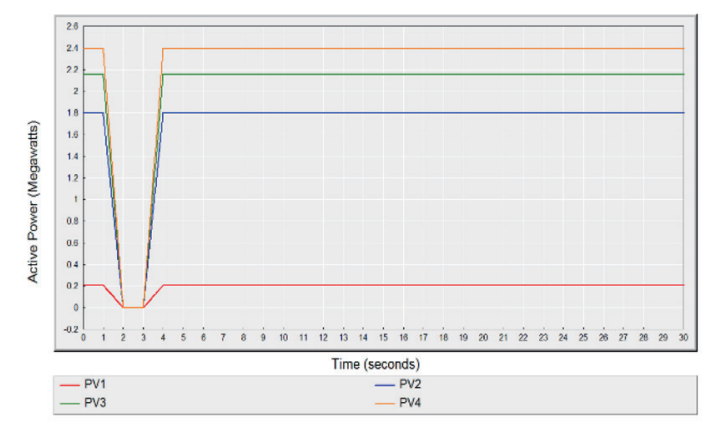

Fig. 9. (Color online) PVPG power variation curves of case WD2C.

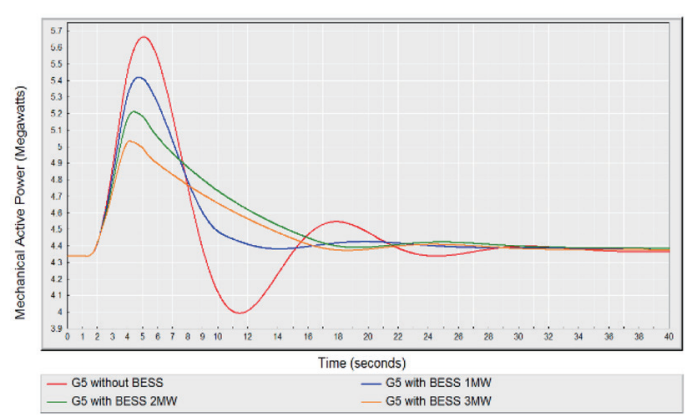

Fig. 11. (Color online) G5 mechanical power response curves of case WD2C.

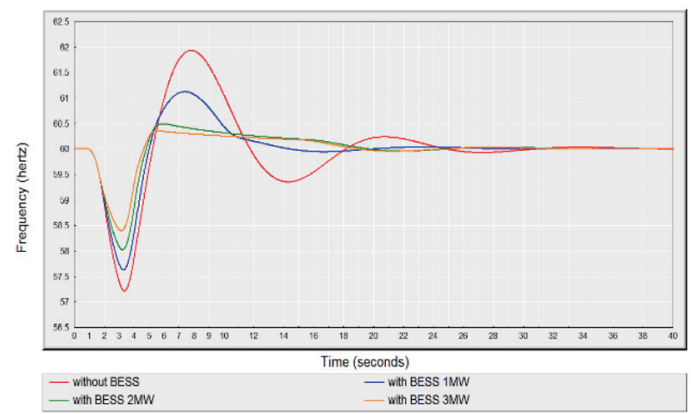

Fig. 10. (Color online) Frequency response curves of case WD2C.

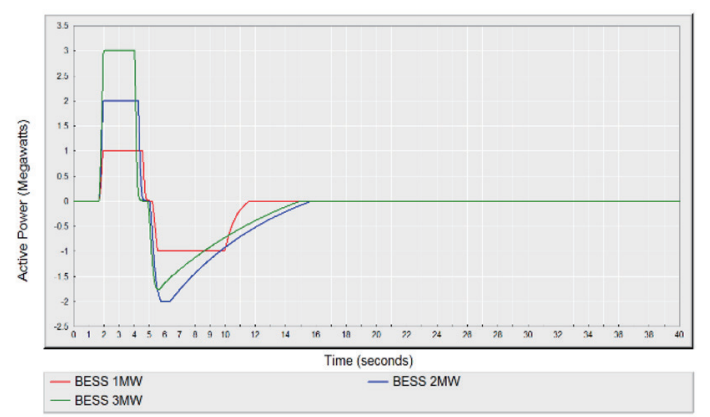

Fig. 12. (Color online) BSS power response curves of case WD2C.

\subsection{Case SD}

The study case SD condition has the highest loading of 57.24 MW. All the power outputs of WPGs and PVPGs are assumed as 6.6 and $6.56 \mathrm{MW}$, respectively. There are two operating dispatches for diesel power plants. One should have six generators in DPP\#1 and one generator in DPP\#2. The other is to have seven generators in DPP\#1 and one generator in DPP\#2. Also, the same disturbance events as those in case WD are used for the simulation. Table 7 gives the operating scenarios and disturbance events of the study case SD.

Table 8 gives the simulation results of the lowest and highest frequencies for each case. It is observed that the lowest frequencies are kept above $57.3 \mathrm{~Hz}$ for all cases except for the case SD1B without the compensation by BSS. A more detailed description of the case SD1B is given below.

A disturbance event of a diesel generator in DPP\#1 with an initial power output of $6.96 \mathrm{MW}$ tripped at $1 \mathrm{~s}$. After the tripping of the diesel generator, the frequency declined rapidly as shown in Fig. 13. It is observed that the system frequency dropped to the lowest value of $57.28 \mathrm{~Hz}$ and then recovered slowly for the system without the compensation by BSS. However, the lowest frequencies improved to the values of $57.72,58.10$, and $58.46 \mathrm{~Hz}$ for the BSS with 1 , 
Table 7

Operating scenarios and events for study case SD.

\begin{tabular}{|c|c|c|c|}
\hline Case & Generators in service & Power output of REs (MW) & Disturbance event \\
\hline \multirow{2}{*}{ SD1A } & 6 in DPP\#1 & WPG:6.6 & \multirow{2}{*}{ Tripping of all WPG systems } \\
\hline & 1 in DPP\#2 & PVPG:6.56 & \\
\hline \multirow{2}{*}{ SD1B } & 6 in DPP\#1 & WPG:6.6 & \multirow{2}{*}{ Tripping of one generator } \\
\hline & 1 in DPP\#2 & PVPG:6.56 & \\
\hline \multirow{2}{*}{ SD1C } & 6 in DPP\#1 & WPG:6.6 & \multirow{2}{*}{$\begin{array}{c}\text { All PVPGs occur } \\
\text { with an RR of } 100 \% / \mathrm{s}\end{array}$} \\
\hline & 1 in DPP\#2 & PVPG:6.56 & \\
\hline \multirow{2}{*}{$\mathrm{SD} 2 \mathrm{~A}$} & 7 in DPP\#1 & WPG:6.6 & \multirow{2}{*}{ Tripping of all WPG systems } \\
\hline & 1 in DPP\#2 & PVPG:6.56 & \\
\hline \multirow{2}{*}{ SD2B } & 7 in DPP\#1 & WPG:6.6 & \multirow{2}{*}{ Tripping of one generator } \\
\hline & 1 in DPP\#2 & PVPG:6.56 & \\
\hline \multirow{2}{*}{$\mathrm{SD} 2 \mathrm{C}$} & 7 in DPP\#1 & WPG:6.6 & \multirow{2}{*}{$\begin{array}{c}\text { All PVPGs occur } \\
\text { with an RR of } 100 \% / \mathrm{s}\end{array}$} \\
\hline & 1 in DPP\#2 & PVPG:6.56 & \\
\hline
\end{tabular}

Table 8

Highest and lowest frequencies for study case SD.

\begin{tabular}{lccc}
\hline Case & Lowest frequency $(\mathrm{Hz})$ & Highest frequency $(\mathrm{Hz})$ & PCS capacity of BSS (MW) \\
\hline \multirow{3}{*}{ SD1A } & 57.86 & 59.61 & 0 \\
& 58.16 & 59.59 & 1 \\
& 58.50 & 59.58 & 2 \\
& 58.80 & 59.57 & 3 \\
SD1B & 57.28 & 58.41 & 0 \\
& 57.72 & 59.21 & 1 \\
& 58.10 & 59.33 & 2 \\
& 58.46 & 59.39 & 3 \\
SD1C & 58.20 & 61.20 & 0 \\
& 58.43 & 60.70 & 1 \\
& 58.65 & 60.41 & 2 \\
& 58.85 & 60.32 & 3 \\
SD2A & 58.28 & 60.48 & 0 \\
& 58.54 & 60.19 & 2 \\
& 58.78 & 60.07 & 3 \\
\hline & 59.00 & 60.07 & 0 \\
SD2B & 58.34 & 60.46 & 1 \\
& 58.63 & 60.17 & 2 \\
& 58.89 & 60.10 & 3 \\
\hline & 59.12 & 60.10 & 0 \\
SD2C & 58.55 & 60.93 & 1 \\
& 58.72 & 60.56 & 3 \\
\hline
\end{tabular}

2, and 3 MW PCS capacities, respectively. Figure 14 shows the mechanical power responses of G5 at DPP\#1. Moreover, the BSS discharged rapidly to its maximum power output of the PCS as shown in Fig. 15. 


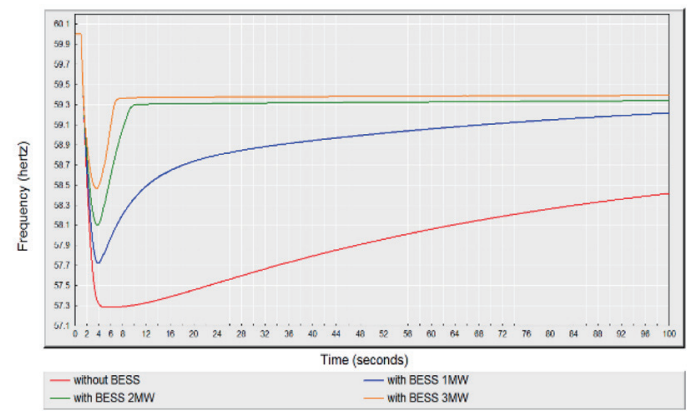

Fig. 13. (Color online) Frequency response curves of case SD1B.

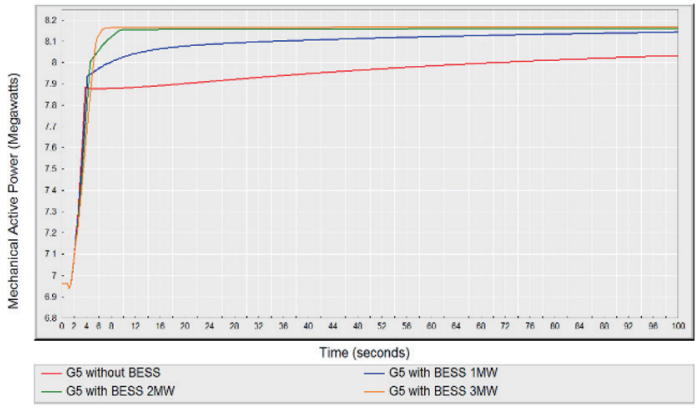

Fig. 14. (Color online) G5 mechanical power response curves of case SD1B.

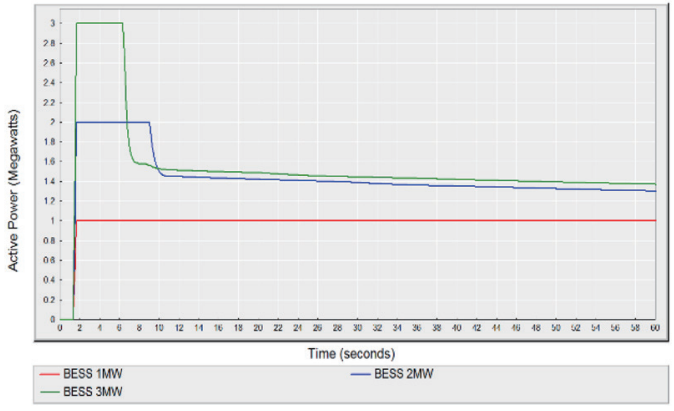

Fig. 15. (Color online) BSS power response curves of case SD1B.

\section{Conclusions}

We selected an island microgrid to verify the effectiveness of a BSS in controlling frequency variation. A novel FSBC of the BSS is proposed and it is not shown in other systems. Peak and off-peak loading scenarios with the disturbance events of WPG tripping, diesel generator tripping, and PVPG power ramping are considered in the simulation. It is found that the lowest frequency below $57.3 \mathrm{~Hz}$ appeared in many simulation cases, resulting in the tripping of the load. However, it can be improved significantly if the novel FSBC of the BSS is applied to assist the operation of the microgrid.

\section{Acknowledgments}

This work was supported by the MOST of Taiwan (MOST 108-3116-F-042A-004-CC2).

\section{References}

1 M. J. E. Alam, K. M. Muttaqi, and D. Sutanto: IEEE Trans. Energy Conver. 29 (2014) 507. https://doi. org/10.1109/TEC.2014.2304951

2 A. Arulampalam, M. Barnes, N. Jenkins, and J. B. Ekanayake: IEE Proc. Generation, Transmission and Distribution 153 (2006) 701. https://doi.org/10.1049/ip-gtd:20045269 
3 R. Khalghani, J. Solanki, S. K. Solanki, and A. Sargolzaei: Proc. 2018 IEEE Int. Conf. Environment and Electrical Engineering and 2018 IEEE Industrial and Commercial Power Systems Europe (IEEE, 2018) 1-6. https://doi.org/10.1109/EEEIC.2018.8494474

4 R. Khalghani, S. K. Solanki, and J. Solanki: Proc. 2017 North American Power Symposium (2017) 1-6. https:// doi.org/10.1109/NAPS.2017.8107340

5 G. V. B. Kumar, G. Anil Kumar, S. Eswararao, and D. Gehlot: Proc. 2018 Int. Conf. Computation of Power, Energy, Information and Communication (2018). https://doi.org/10.1109/ICCPEIC.2018.8525173

6 X. Li and D. Zhang: Proc. 2018 Int. Conf. Advanced Mechatronic Systems (2018) 1-5. https://doi.org/10.1109/ ICAMechS.2018.8506868

7 World Energy Council: https://www.worldenergy.org/assets/downloads/Resources-E-storagereport-2016.02.04.pdf.

8 D. Rastler: EPRI Technical Report (2010) 1020676.

9 B. Seal: EPRI Project (2014) 3002002233.

10 C. T. Hsu, T. J. Cheng, H. M. Huang, Y. D. Lee, Y. R. Chang, and J. L. Jiang: Micro. Rel. 92 (2019) 42. https:// doi.org/10.1016/j.microrel.2018.11.011

11 C. C. Yeh, C. S. Chen, T. T. Ku, C. H. Lin, C. T. Hsu, Y. R. Chang, and Y. D. Lee: IEEE Trans. Ind. Appl. 53 (2017) 947. https://doi.org/10.1109/TIA.2016.2627518

12 D. Cormode, A. D. Cronin, W. Richardson, A. T. Lorenzo, A. E. Brooks, and D. N. D. Giustina: Proc. IEEE Photovoltaic Specialists Conf. (IEEE, 2013) 1805-1810. https://doi.org/10.1109/PVSC.2013.6744493.

13 V. Salehi and B. Radibratovic: Proc. IEEE PES General Meeting (IEEE, 2014) 1-5. https://doi.org/10.1109/ PESGM.2014.6938985

14 IEEE: IEEE Std 421.5-2016 (2016). https://doi.org/10.1109/IEEESTD.2016.7553421

15 CYME Int. Inc.: http://www.cyme.com

\section{About the Authors}

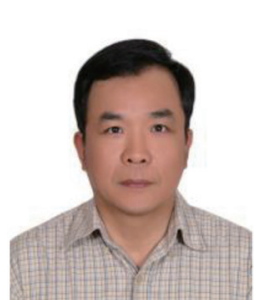

Cheng-Ting Hsu was born in Taiwan in 1963. He received his Ph.D. degree in electrical engineering from National Sun Yat-Sen University, Taiwan, in 1995. He is currently a professor of electrical engineering at Southern Taiwan University of Science and Technology, Taiwan. His interests are in the computer control of power systems, smart grids, and renewable energy. (cthsu@stust.edu.tw)

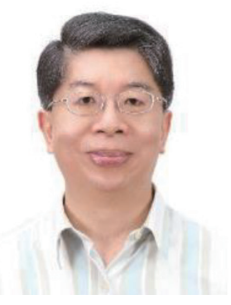

Tsun-Jen Cheng was born in Taiwan in 1958. He received his B.S.E.E. from National Chiao Tung University, Taiwan and his M.S.E.E. from Arizona State University, USA. He is currently a lecturer at Southern Taiwan University of Science and Technology, Taiwan. His interests are in control systems and microprocessor applications. (chengtj@stust.edu.tw)

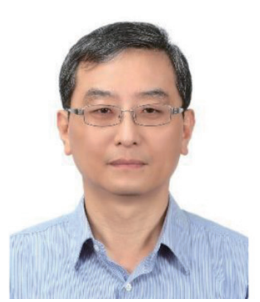

Hung-Ming Huang was born in Taiwan in 1961. He received his Ph.D. degree in electrical engineering from National Taiwan University, Taiwan, in 1994. He is currently an assistant professor of electrical engineering at Southern Taiwan University of Science and Technology, Taiwan. His interests are in power system analysis and microprocessor applications.

(hhm3333@stust.edu.tw) 